\title{
Cancer Radiotherapy: Understanding the Price of Tumor Eradication
}

\author{
Olga A. Martin ${ }^{1 *}$ and Roger F. Martin ${ }^{2}$ \\ ${ }^{1}$ Sir Peter MacCallum Department of Oncology, The University of Melbourne, Melbourne, VIC, Australia, ${ }^{2}$ School of \\ Chemistry, The University of Melbourne, Melbourne, VIC, Australia
}

Keywords: cancer radiotherapy, quality of life, normal tissue toxicity, aging, systemic effects, DNA damage, DNA repair, radioprotectors

OPEN ACCESS

Edited by:

Liz Caldon,

Garvan Institute of Medical

Research, Australia

Reviewed by:

Alexandros G. Georgakilas,

National Technical University of

Athens, Greece

Michael Jackson,

University of New South

Wales, Australia

*Correspondence:

Olga A. Martin

olga.martin@petermac.org

Specialty section:

This article was submitted to

Cell Growth and Division,

a section of the journal

Frontiers in Cell and Developmental

Biology

Received: 13 December 2019 Accepted: 27 March 2020

Published: 24 April 2020

Citation:

Martin OA and Martin RF (2020) Cancer Radiotherapy: Understanding

the Price of Tumor Eradication.

Front. Cell Dev. Biol. 8:261.

doi: 10.3389/fcell.2020.00261
Cancer radiotherapy (RT) is involved in the treatment of more than a half of all cancer patients, because it is highly effective; 40\% of cancer cures can be attributed to RT (Baskar et al., 2012). Moreover, the efficacy of RT is steadily improving, largely due to the striking progress in technology, aimed at maximizing the radiation dose to the tumor and minimizing the dose to normal tissues. This continual improvement contributes to the increasing numbers of cancer survivors. In Australia, the 5-years relative survival from all cancers (excluding skin cancer) increased from $48 \%$ in $1984-1988$ to $68 \%$ in $2009-2013^{1}$. In $2012,410,530$ ex-cancer patients were alive 5 years after treatment; $1.8 \%$ of the population. In the USA, there are now $14 \mathrm{M}$ cancer survivors; $\sim 4 \%$ of the population (Travis, 2006; Travis et al., 2013). Accordingly, increasing attention is now directed to the quality of life (QoL) of cancer survivors, particularly to treatment-related toxicities (Stone et al., 2003; De Ruysscher et al., 2019), as highlighted in a recent report from the National Cancer Research Institute in the $\mathrm{UK}^{2}$.

Normal tissue toxicity from RT can be attributed to three different etiologies. The most obvious of these can be defined as "targeted", due to relatively high radiation doses to normal tissues in the vicinity of a tumor. Ironically, the technological improvements in dose delivery that have diminished this problem, have contributed to the second category of normal tissue toxicity. Modern RT techniques (e.g., Intensity-Modulated RT, IMRT) use multiple moving beams that sculpt a volume of high dose encompassing the tumor, so quite large volumes of normal tissues are 'bathed' in low doses, within and between beams (Kry et al., 2005; Harrison, 2017). This category also includes scattered radiation that spreads out in different directions from each radiation beam. The third category can be considered as "systemic," reflecting the radiation-induced abscopal ("out-of-field") effect (RIAE). This is attributed to the localized stress in the irradiated volume, that triggers a systemic biological response that is propagated to sites distant from the irradiated volume, and is largely mediated by the immune system (Reynders et al., 2015; Siva et al., 2015). In a sense, the RIAE can be considered as the systemic counterpart of the cellular radiation-induced bystander effect (RIBE), although the historical understanding of the phenomena was quite different. The recognition of the RIBE (Nagasawa and Little, 1992; Prise and O'Sullivan, 2009) is much more recent, compared to early observations the RIAE by radiation oncologists, that manifest both as out-of-field tumor responses and out-of-field RT-associated toxicities (Mole, 1953; Siva et al., 2015).

The best-known RT-induced normal tissue toxicities are targeted effects (tissue responses in the higher dose volume), the subject of many classical and contemporary radiobiological studies (Stewart and Dorr, 2009). They can be acute (appear within weeks of irradiation), late (months to years after RT), or both. For targeted effects, there is a wide spectrum of individual radiosensitivity (RS) manifested as normal tissue toxicity (Barnett et al., 2009). Low dose- and RIAE-generated "silent" toxicities, e.g., chronic inflammatory responses and mutagenesis in radiosensitive tissues,

\footnotetext{
${ }^{1}$ Cancer in Australia Australian Association of Cancer Registries, 2017.

${ }^{2}$ https://www.ncri.org.uk/lwbc/
} 
can also lead to long-term tissue dysfunction, even for future generations (Dubrova, 2003). Just as it is well-established for targeted effects, one can expect that there will be a spectrum of individual RS for low dose and systemic effects.

Epidemiological findings in long-term cancer survivors treated with RT indicate the increased incidence of degenerative pathological conditions normally associated with aging, or age-related diseases (e.g., cardio- and cerebrovascular disorders, neurodegeneration including dementia, hormonal disturbances, cataracts, bone marrow insufficiency, immune system dysfunction, second cancers, and overall life shortening) (Cupit-Link et al., 2017). Evidence is accumulating for similar consequences of low dose IR exposure (Majer et al., 2014; Harrison, 2017). Therefore, aging may be the common link between the diverse late morbidities and RT. By amplifying the mechanisms that are responsible for cellular aging (Sabatier et al., 1995; Dubrova et al., 2002; Dubrova, 2003; Miller et al., 2008; Paulino et al., 2010; Azzam et al., 2012; Sabatino et al., 2012; Merrifield and Kovalchuk, 2013; Ungvari et al., 2013; Sprung et al., 2015; Shimura et al., 2016; Yin et al., 2018), RT may induce a premature aging manifested as an accelerated onset of chronic degenerative disorders in some patients. Figure 1 highlights the similarities between the response to IR and aging, but there are some differences, e.g., differences in the spectra and severity of DNA lesions (Nikitaki et al., 2015). Premature cellular senescence (Nakamura et al., 2008) is also an important common feature of the two pathologies. It is important to note that the idea of RT-induced accelerated aging is not a new one (Richardson, 2009), but given the growing aging population, it has increasingly important consequences for the cost of community health care. Moreover, the availability of improved biomarkers provides a means of monitoring both the need for intervention, and the efficacy of proposed interventions.

Therefore, to fully understand the role of RT in accelerating the aging process, research aimed at the following objectives is required: (1) Development of a "signature" profile of systemic markers to identify RT cancer patients susceptible to development of premature aging; (2) Improving mechanistic understanding of systemic propagation of genotoxic events and the associated aging phenotype following local exposure to IR; (3) Development of strategies for prevention, protection and mitigation of RT-related systemic genotoxic events.

\section{IDENTIFICATION OF A SIGNATURE OF SYSTEMIC MARKERS FOR PREMATURE AGING IN RT CANCER PATIENTS}

The kinetics of aging biomarkers could be monitored in blood of RT-treated cancer patients and compared with the pre-treatment values. Suitable patients, scheduled for treatment with RT, would be $<50-60$ years of age, and without evidence of non-cancer morbidities at the time of work-up. Examples of a suitable cohort would be breast or head \& neck cancer patients, with an anticipated 5 -years survival $>90 \%$.

Studies indicate that accumulated unrepaired systemic DNA damage underlies RT-induced pathologies (De Ruysscher et al.,

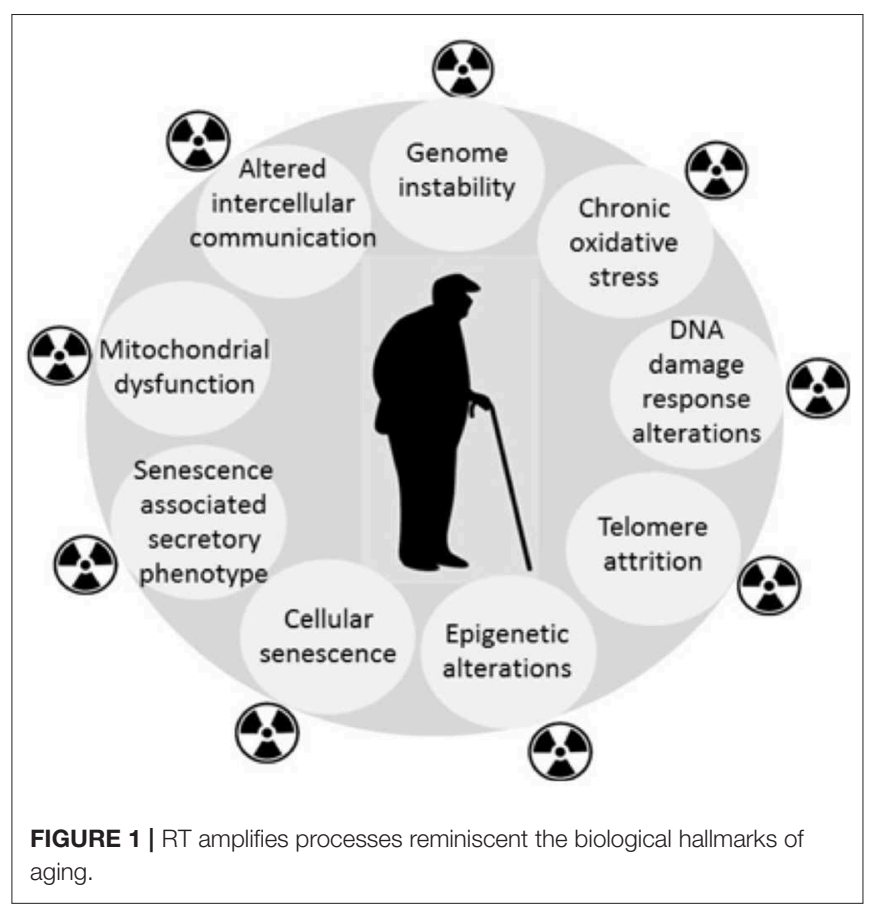

2019). The DNA damage response (DDR) varies in young, mature and old mice, slow down with age, making old mice the most vulnerable to radiation effects (Kovalchuk et al., 2014). DDR declines in senescent cells and during normal and premature human aging (Sedelnikova et al., 2008), and individual RS continuously rises with age (Schuster et al., 2018). Novel functional assays of radiation-induced DNA damage recognition and repair efficiency in ex-vivo irradiated primary human fibroblasts and peripheral blood mononuclear cells (PBMC) have been recently developed. The tests are based on post-irradiation formation of nuclear repair foci at the sites of DNA double-strand breaks (DSBs) for two DNA damage markers, phosphorylated ATM kinase ("ATM nucleo-shuttling") (Bodgi and Foray, 2016; Pereira et al., 2018) and histone H2AX ( $\gamma$-H2AX) (Martin et al., 2013; Lobachevsky et al., 2015a, 2016). Both assays efficiently separated radiosensitive individuals with impaired DDR from those with normal RS. In our retrospective study, ex-RT patients who had documented to have severe RT-induced toxicity (and matched controls who responded normally) were recalled for blood sampling. A novel statistical algorithm was developed by Lobachevsky et al. (2016), based on non-linear regression analysis of the kinetics of repair of $\gamma-\mathrm{H} 2 \mathrm{AX}$ foci, following exvivo irradiation of the PBMC. Subsequently the same dataset was analyzed by Bayesian modeling (Herschtal et al., 2018). Both methods of analysis distinguished the radiosensitive patients from controls, but the Bayesian statistics also outlined the importance of assessment of both the initial radiation-induced DNA damage and DNA damage repair. In a later study, the exvivo $\gamma$-H2AX response was assayed in PBMC collected before and during RT, and this showed that RT itself can affect individual $\mathrm{RS}$, as reflected by changes in DSB repair efficiency in PBMC 
(Yin et al., 2018), adding a further dimension to the challenge of implementation.

Also, the number of endogenous $\gamma$-H2AX foci per cell in PBMC of normal individuals increases with age in a linear fashion (Sedelnikova et al., 2008; Schurman et al., 2012). The outliers identified in the linear regression analysis (Schurman et al., 2012) included elevated $\gamma$-H2AX foci/cell in patients with clinical morbidities. Interestingly, DDR has been linked with the immune response for normal and tumor tissues, as evidenced by cumulative bioinformatics studies (Georgakilas et al., 2015).

Therefore, the numbers of $\gamma-\mathrm{H} 2 \mathrm{AX}$ foci/cell and efficiency of DDR in PBMC could provide a basis for identification of RT patients susceptible to RT-induced premature aging. However, it is more likely that a combination of markers will be required to constitute an effective "signature" to identify patients requiring added attention. Candidates for such auxiliary biomarkers include those reflecting immune and epigenetic alterations, increased immune cell senescence, oxidative stress, and mitochondrial dysfunction.

\section{IMPROVING THE MECHANISTIC UNDERSTANDING OF SYSTEMIC PROPAGATION OF GENOTOXIC EVENTS AND THE ASSOCIATED AGING PHENOTYPE FOLLOWING LOCAL EXPOSURE TO IR}

Conventional RT triggers systemic biological effects in animal models (Koturbash et al., 2006, 2008; Mancuso et al., 2008), but due to significant scatter, RIAEs are difficult to interpret. The scatter problem associated with conventional radiation sources is much reduced with Synchrotron radiation, providing a useful tool to study RIAE. The defined geometry and coherence of the synchrotron beam delivers IR to small volumes with lower scatter, and the high dose rate (up to $>1,000 \mathrm{~Gy} / \mathrm{sec}$ ) minimizes motion artifacts, but also introduces the "FLASH" effect (Durante et al., 2018). Ventura et al. (2017) reported that that various synchrotron settings (IR dose, volume, beam modality) trigger similar systemic effects in normal mouse tissues of wild-type C57BL/6 mice. Depending on the level of scatter radiation (Lobachevsky et al., 2015b), these effects were attributed to either true abscopal signaling, or to direct low-dose scatter radiation. RIAE was abrogated in mice with immune deficiencies, e.g., in mice with non-functional macrophages (Lobachevsky et al., 2019). Possible extensions of these studies using synchrotron irradiation include comparison of targeted and out-of-field effects of IR in young and old mice of wild-type and immunedeficient strains, as well as verification of salient features using a model with conventional radiation beams. The objective would be to understand the pathways by which IR modulates the aging processes in various organs crucial for the development of IR-related late pathologies (e.g., spleen, bone marrow, heart, vasculature, gonads, brain). These experimental models could also be used to evaluate potential therapeutic targets that emerge from the clinical studies described in the previous section.

\section{DEVELOPMENT OF STRATEGIES FOR PREVENTION, PROTECTION AND MITIGATION OF RT-RELATED SYSTEMIC GENOTOXIC EVENTS}

Targeted radiation effects and RIAE are both associated with elevated DNA damage and genome instability mediated by reactive oxygen species (ROS), so it is critical that any strategy aimed at reducing systemic genotoxic events does not compromise the cancer therapy, mediated by targeted radiation effects. Similarly, whilst normal tissue toxicities associated RIAE are mediated by the immune response, the tumor response to RT also involves the immune response (Haikerwal et al., 2015; Xing et al., 2019). However, kinetic studies on the impact with immunomodulators on the response of targeted tumors, out-of-field metastases and RIAE in normal tissues may reveal differences in response kinetics enabling selective suppression of RIAE in normal tissues. Such kinetic differences enabled scatter effects to be distinguished from the systemic RIAE (Ventura et al., 2017).

Our mouse studies revealed that molecules that block cytokines/cytokine receptors and macrophages can be expected to mitigate abscopal genotoxic events in normal tissues (Ventura et al., 2017; Lobachevsky et al., 2019). Our extensive review of potential strategies for prevention of RT-induced second cancers (Martin et al., 2016) illustrates the range of approaches that can be considered for all toxicities mediated by RIAE. A review on radiation-induced cardiotoxicity (Stewart et al., 2013), which noted the role of systemic effects, also discussed strategies for prevention. Another report extensively reviewed strategies for amelioration of radiation effects on the eye (Kleiman et al., 2017), some of which could be applicable to RT. In this context, a relatively new family of radioprotectors developed by one of the authors (RFM) is of interest. The first example, methylproamine (Martin et al., 2004), is a potent radioprotector in vitro; a dose modification factor of 2.0 at a concentration of $10 \mathrm{uM}$ (Lobachevsky et al., 2011) and improved analogs, including in vivo activity, have been reported in the patent literature (Martin et al., 2011). Such radioprotectors have the potential to take advantage of the slow kinetics observed for the RIAE, illustrated by the report of the delayed appearance of DNA damage in eyebrow hair follicles after RT of lung cancer patients; $24 \mathrm{~h}$ after the first fraction (Siva et al., 2015). A delayed DDR is well-established for the cellular RIBE (Sedelnikova et al., 2007). Interestingly, methylproamine protects bystander cells in the in vitro RIBE setting, e.g., if present with recipient cells at the time of transfer of media irradiated cells (BurdakRothkamm et al., 2015). By contrast, in the context of targeted radiation effects, methylproamine must be present before and during irradiation to endow radioprotection of cultured cells (Lobachevsky et al., 2011), consistent with the mechanism (DNAbinding antioxidant) of radioprotection (Martin and Anderson, 1998). Thus, one can envisage an RT scenario in which such radioprotectors could be administered after irradiation, and thus not compromise response of the tumor, but nevertheless mitigate the subsequent RIAE mediated toxicity in normal tissues. 
Whilst scheduling that avoids the possibility of compromising the tumor response might be challenging in the setting of conventional fractionation, this would be less problematical for hypofractionation modalities.

\section{CONCLUSIONS}

RT has an established role in cancer therapy and is unlikely to be superseded in the foreseeable future. In addition to pursuing better treatments, it is time now for more focus on the QoL of cancer RT survivors. The priorities include the need to understand the biological basis of treatment side-effects and their management, and, in particular, the mechanisms responsible for RT-induced aging phenotype and associated pathologies. This new knowledge is expected to enable development of systemic markers to identify patients most susceptible to accelerated aging, and the early stages of that process, as well as novel interventions

\section{REFERENCES}

Azzam, E. I., Jay-Gerin, J. P., and Pain, D. (2012). Ionizing radiation-induced metabolic oxidative stress and prolonged cell injury. Cancer Lett. 327, 48-60. doi: 10.1016/j.canlet.2011.12.012

Barnett, G. C., West, C. M., Dunning, A. M., Elliott, R. M., Coles, C. E., Pharoah, P. D., et al. (2009). Normal tissue reactions to radiotherapy: towards tailoring treatment dose by genotype. Nat. Rev. Cancer. 9, 134-142. doi: 10.1038/nrc2587

Baskar, R., Lee, K. A., Yeo, R., and Yeoh, K. W. (2012). Cancer and radiation therapy: current advances and future directions. Int. J. Med. Sci. 9, 193-199. doi: $10.7150 /$ ijms. 3635

Bodgi, L., and Foray, N. (2016). The nucleo-shuttling of the ATM protein as a basis for a novel theory of radiation response: resolution of the linear-quadratic model. Int. J. Radiat. Biol. 92, 117-131. doi: 10.3109/09553002.2016.1135260

Burdak-Rothkamm, S., Smith, A., Lobachevsky, P., Martin, R., and Prise, K. M. (2015). Radioprotection of targeted and bystander cells by methylproamine. Strahl. Onkol. 191, 248-255. doi: 10.1007/s00066-014-0751-9

Cupit-Link, M. C., Kirkland, J. L., Ness, K. K., Armstrong, G. T., Tchkonia, T., LeBrasseur, N. K., et al. (2017). Biology of premature ageing in survivors of cancer. ESMO Open. 2:e000250. doi: 10.1136/esmoopen-2017-000250

De Ruysscher, D., Niedermann, G., Burnet, N. G., Siva, S., Lee, A. W. M., and Hegi-Johnson, F. (2019). Radiotherapy toxicity. Nat. Rev. Dis. Primers. 5:13. doi: 10.1038/s41572-019-0064-5

Dubrova, Y. E. (2003). Radiation-induced transgenerational instability. Oncogene 22, 7087-7093. doi: 10.1038/sj.onc.1206993

Dubrova, Y. E., Grant, G., Chumak, A. A., Stezhka, V. A., and Karakasian, A. N. (2002). Elevated minisatellite mutation rate in the post-chernobyl families from ukraine. Am. J. Hum. Genet. 71, 801-809. doi: 10.1086/342729

Durante, M., Brauer-Krisch, E., and Hill, M. (2018). Faster and safer? FLASH ultra-high dose rate in radiotherapy. Br. J. Radiol. 91:20170628. doi: 10.1259/bjr.20170628

Georgakilas, A. G., Pavlopoulou, A., Louka, M., Nikitaki, Z., Vorgias, C. E., Bagos, P. G., et al. (2015). Emerging molecular networks common in ionizing radiation, immune and inflammatory responses by employing bioinformatics approaches. Cancer Lett. 368, 164-172. doi: 10.1016/j.canlet.2015.03.021

Haikerwal, S. J., Hagekyriakou, J., MacManus, M., Martin, O. A., and Haynes, N. M. (2015). Building immunity to cancer with radiation therapy. Cancer Lett. 368, 198-208. doi: 10.1016/j.canlet.2015.01.009

Harrison, R. (2017). Out-of-field doses in radiotherapy: Input to epidemiological studies and dose-risk models. Phys. Med. 42:239-246. doi: 10.1016/j.ejmp.2017.02.001

Herschtal, A., Martin, R. F., Leong, T., Lobachevsky, P., and Martin, O. A. (2018). A bayesian approach for prediction of patient radiosensitivity. Int. J. Radiat. Oncol. Biol. Phys. 102, 627-634. doi: 10.1016/j.ijrobp.2018.06.033 for prevention and mitigation. Thus, the overall objective is early diagnosis, monitoring and management of RT-related morbidities, and identification of those cancer patients at most risk of these morbidities so their treatments can be modified accordingly.

\section{AUTHOR CONTRIBUTIONS}

$\mathrm{OM}$ and RM contributed ideas and wrote the manuscript.

\section{ACKNOWLEDGMENTS}

The authors acknowledge continuous support and advice of clinical colleagues from the Department of Radiation Oncology, Peter MacCallum Cancer Center. OM's membership in the Multidisciplinary European Low-Dose Initiative (MELODI) contributed to her awareness of ionizing radiation-induced premature aging.

Kleiman, N. J., Stewart, F. A., and Hall, E. J. (2017). Modifiers of radiation effects in the eye. Life Sci. Space Res. 15, 43-54. doi: 10.1016/j.lssr.2017.07.005

Koturbash, I., Loree, J., Kutanzi, K., Koganow, C., Pogribny, I., and Kovalchuk, O. (2008). In vivo bystander effect: cranial X-irradiation leads to elevated DNA damage, altered cellular proliferation and apoptosis, and increased p53 levels in shielded spleen. Int. J. Radiat. Oncol. Biol. Phys. 70, 554-562. doi: 10.1016/j.ijrobp.2007.09.039

Koturbash, I., Rugo, R. E., Hendricks, C. A., Loree, J., Thibault, B., Kutanzi, K., et al. (2006). Irradiation induces DNA damage and modulates epigenetic effectors in distant bystander tissue in vivo. Oncogene 25, 4267-4275. doi: $10.1038 /$ sj.onc. 1209467

Kovalchuk, I. P., Golubov, A., Koturbash, I. V., Kutanzi, K., Martin, O. A., and Kovalchuk, O. (2014). Age-dependent changes in DNA repair in radiationexposed mice. Radiat. Res. 182, 683-694. doi: 10.1667/RR13697.1

Kry, S. F., Salehpour, M., Followill, D. S., Stovall, M., Kuban, D. A., White, R. A., et al. (2005). The calculated risk of fatal secondary malignancies from intensitymodulated radiation therapy. Int. J. Radiat. Oncol. Biol. Phys. 62, 1195-1203. doi: 10.1016/j.ijrobp.2005.03.053

Lobachevsky, P., Ivashkevich, A., Forrester, H. B., Stevenson, A. W., Hall, C. J., Sprung, C. N., et al. (2015b). Assessment and implications of scattered microbeam and broadbeam synchrotron radiation for bystander effect studies. Radiat. Res. 184, 650-659. doi: 10.1667/RR13720.1

Lobachevsky, P., Leong, T., Daly, P., Smith, J., Best, N., Tomaszewski, J., et al. (2016). Compromized DNA repair as a basis for identification of cancer radiotherapy patients with extreme radiosensitivity. Cancer Lett. 383, 212-219. doi: 10.1016/j.canlet.2016.09.010

Lobachevsky, P., Woodbine, L., Hsiao, K. C., Choo, S., Fraser, C., Gray, P., et al. (2015a). Evaluation of severe combined immunodeficiency and combined immunodeficiency pediatric patients on the basis of cellular radiosensitivity. J. Mol. Diagnost. 17, 560-575. doi: 10.1016/j.jmoldx.2015. 05.004

Lobachevsky, P. N., Vasireddy, R. S., Broadhurst, S., Sprung, C. N., Karagiannis, T. C., Smith, A. J., et al. (2011). Protection by methylproamine of irradiated human keratinocytes correlates with reduction of DNA damage. Int. J. Radiat. Biol. 87, 274-283. doi: 10.3109/09553002.2011.530333

Lobachevsky, P. N., Ventura, J., Giannakandropoulou, L., Forrester, H., Palazzolo, J. S., Haynes, N. M., et al. (2019). A functional immune system is required for the systemic genotoxic effects of localized irradiation. Int. J. Radiat. Oncol. Biol. Phys. 103, 1184-1193. doi: 10.1016/j.ijrobp.2018.11.066

Majer, M., Knezevic, Z., and Saveta, M. (2014). Current trends in estimating risk of cancer from exposure to low doses of ionising radiation. Arh. Hig. Rada Toksikol. 65, 251-257. doi: 10.2478/10004-1254-65-2014-2425

Mancuso, M., Pasquali, E., Leonardi, S., Tanori, M., Rebessi, S., Di Majo, V., et al. (2008). Oncogenic bystander radiation effects in Patched heterozygous 
mouse cerebellum. Proc. Natl. Acad. Sci. U.S.A. 105, 12445-12450. doi: 10.1073/pnas.0804186105

Martin, O. A., Ivashkevich, A., Choo, S., Woodbine, L., Jeggo, P. A., Martin, R. F., et al. (2013). Statistical analysis of kinetics, distribution and colocalisation of DNA repair foci in irradiated cells: cell cycle effect and implications for prediction of radiosensitivity. DNA Repair. 12, 844-855. doi: 10.1016/j.dnarep.2013.07.002

Martin, O. A., Yin, X., Forrester, H. B., Sprung, C. N., and Martin, R. F. (2016). Potential strategies to ameliorate risk of radiotherapyinduced second malignant neoplasms. Semin. Cancer Biol. 37-38, 65-76. doi: 10.1016/j.semcancer.2015.12.003

Martin, R., Francis, W.hite J., Lobachevsky, P., Winkler, D., Skene, C., and Marcuccio, S. (2011). Radioprotector Compounds and Methods. Patent WO/2011/123890. Melbourne, Australia.

Martin, R. F., and Anderson, R. F. (1998). Pulse radiolysis studies indicate that electron transfer is involved in radioprotection by Hoechst 33342 and methylproamine. Int. J. Radiat. Oncol. Biol. Phys. 42, 827-831. doi: 10.1016/S0360-3016(98)00316-2

Martin, R. F., Broadhurst, S., Reum, M. E., Squire, C. J., Clark, G. R., Lobachevsky, P. N., et al. (2004). In vitro studies with methylproamine: a potent new radioprotector. Cancer Res. 64, 1067-1070. doi: 10.1158/0008-5472.CAN-03-2423

Merrifield, M., and Kovalchuk, O. (2013). Epigenetics in radiation biology: a new research frontier. Front. Genet. 4:40. doi: 10.3389/fgene.2013.00040

Miller, J. H., Jin, S., Morgan, W. F., Yang, A., Wan, Y., Aypar, U., et al. (2008). Profiling mitochondrial proteins in radiation-induced genome-unstable cell lines with persistent oxidative stress by mass spectrometry. Radiat. Res. 169, 700-706. doi: 10.1667/RR1186.1

Mole, R. H. (1953). Whole body irradiation; radiobiology or medicine? Br. J. Radiol. 26, 234-241. doi: 10.1259/0007-1285-26-305-234

Nagasawa, H., and Little, J. B. (1992). Induction of sister chromatid exchanges by extremely low doses of alpha-particles. Cancer Res. 52, 6394-6396.

Nakamura, A. J., Chiang, Y. J., Hathcock, K. S., Horikawa, I., Sedelnikova, O. A., Hodes, R. J., et al. (2008). Both telomeric and non-telomeric DNA damage are determinants of mammalian cellular senescence. Epigenetics Chromatin. 1:6. doi: 10.1186/1756-8935-1-6

Nikitaki, Z., Hellweg, C. E., Georgakilas, A. G., and Ravanat, J. L. (2015). Stressinduced DNA damage biomarkers: applications and limitations. Front Chem. 3:35. doi: 10.3389/fchem.2015.00035

Paulino, A. C., Constine, L. S., Rubin, P., and Williams, J. P. (2010). Normal tissue development, homeostasis, senescence, and the sensitivity to radiation injury across the age spectrum. Semin. Radiat. Oncol. 20, 12-20. doi: 10.1016/j.semradonc.2009.08.003

Pereira, S., Bodgi, L., Duclos, M., Canet, A., Ferlazzo, M. L., Devic, C., et al. (2018). Fast and binary assay for predicting radiosensitivity based on the theory of ATM nucleo-shuttling: development, validation, and performance. Int. J. Radiat. Oncol. Biol. Phys. 100, 353-360. doi: 10.1016/j.ijrobp.2017.10.029

Prise, K. M., and O’Sullivan, J. M. (2009). Radiation-induced bystander signalling in cancer therapy. Nat. Rev. Cancer. 9, 351-360. doi: 10.1038/nrc2603

Reynders, K., Illidge, T., Siva, S., Chang, J. Y., and De Ruysscher, D. (2015). The abscopal effect of local radiotherapy: using immunotherapy to make a rare event clinically relevant. Cancer Treat. Rev. 41, 503-510. doi: 10.1016/j.ctrv.2015.03.011

Richardson, R. B. (2009). Ionizing radiation and aging: rejuvenating an old idea. Aging 1, 887-902. doi: 10.18632/aging.100081

Sabatier, L., Lebeau, J., and Dutrillaux, B. (1995). Radiation-induced carcinogenesis: individual sensitivity and genomic instability. Radiat. Environ. Biophys. 34, 229-232. doi: 10.1007/BF01209747

Sabatino, L., Picano, E., and Andreassi, M. G. (2012). Telomere shortening and ionizing radiation: a possible role in vascular dysfunction? Int. J. Radiat. Biol. 88, 830-839. doi: 10.3109/09553002.2012.709307

Schurman, S. H., Dunn, C. A., Greaves, R., Yu, B., Ferrucci, L., Croteau, D. L., et al. (2012). Age-related disease association of endogenous gamma-H2AX foci in mononuclear cells derived from leukapheresis. PLoS ONE. 7:e45728. doi: 10.1371/journal.pone.0045728

Schuster, B., Ellmann, A., Mayo, T., Auer, J., Haas, M., Hecht, M., et al. (2018). Rate of individuals with clearly increased radiosensitivity rise with age both in healthy individuals and in cancer patients. BMC Geriatr. 18:105. doi: 10.1186/s12877-018-0799-y
Sedelnikova, O. A., Horikawa, I., Redon, C., Nakamura, A., Zimonjic, D. B., Popescu, N. C., et al. (2008). Delayed kinetics of DNA double-strand break processing in normal and pathological aging. Aging Cell. 7, 89-100. doi: 10.1111/j.1474-9726.2007.00354.x

Sedelnikova, O. A., Nakamura, A., Kovalchuk, O., Koturbash, I., Mitchell, S. A., Marino, S. A., et al. (2007). DNA double-strand breaks form in bystander cells after microbeam irradiation of three-dimensional human tissue models. Cancer Res. 67, 4295-4302. doi: 10.1158/0008-5472.CAN06-4442

Shimura, T., Kobayashi, J., Komatsu, K., and Kunugita, N. (2016). Severe mitochondrial damage associated with low-dose radiation sensitivity in ATM- and NBS1-deficient cells. Cell Cycle. 15, 1099-1107. doi: 10.1080/15384101.2016.1156276

Siva, S., MacManus, M. P., Martin, R. F., and Martin, O. A. (2015). Abscopal effects of radiation therapy: a clinical review for the radiobiologist. Cancer Lett. 356, 82-90. doi: 10.1016/j.canlet.2013.09.018

Sprung, C. N., Ivashkevich, A., Forrester, H. B., Redon, C. E., Georgakilas, A., and Martin, O. A. (2015). Oxidative DNA damage caused by inflammation may link to stress-induced non-targeted effects. Cancer Lett. 356, 72-81. doi: 10.1016/j.canlet.2013.09.008

Stewart, F. A., and Dorr, W. (2009). Milestones in normal tissue radiation biology over the past 50 years: from clonogenic cell survival to cytokine networks and back to stem cell recovery. Int. J. Radiat. Biol. 85, 574-586. doi: 10.1080/09553000902985136

Stewart, F. A., Seemann, I., Hoving, S., and Russell, N. S. (2013). Understanding radiation-induced cardiovascular damage and strategies for intervention. Clin. Oncol. 25, 617-624. doi: 10.1016/j.clon.2013.06.012

Stone, H. B., Coleman, C. N., Anscher, M. S., and McBride, W. H. (2003). Effects of radiation on normal tissue: consequences and mechanisms. Lancet Oncol. 4, 529-536. doi: 10.1016/S1470-2045(03)01191-4

Travis, L. B. (2006). The epidemiology of second primary cancers. Cancer Epidemiol. Biomarkers Prev. 15, 2020-2026. doi: 10.1158/1055-9965.EPI-06-0414

Travis, L. B., Demark Wahnefried, W., Allan, J. M., Wood, M. E., and $\mathrm{Ng}$, A. K. (2013). Aetiology, genetics and prevention of secondary neoplasms in adult cancer survivors. Nat. Rev. Clin. Oncol. 10, 289-301. doi: 10.1038/nrclinonc.2013.41

Ungvari, Z., Podlutsky, A., Sosnowska, D., Tucsek, Z., Toth, P., Deak, F., et al. (2013). Ionizing radiation promotes the acquisition of a senescence-associated secretory phenotype and impairs angiogenic capacity in cerebromicrovascular endothelial cells: role of increased DNA damage and decreased DNA repair capacity in microvascular radiosensitivity. J. Gerontol. Series A Biol. Sci. Med. Sci. 68, 1443-1457. doi: 10.1093/gerona/glt057

Ventura, J., Lobachevsky, P. N., Palazzolo, J. S., Forrester, H., Haynes, N. M., Ivashkevich, A., et al. (2017). Localized synchrotron irradiation of mouse skin induces persistent systemic genotoxic and immune responses. Cancer Res. 77, 6389-6399. doi: 10.1158/0008-5472.CAN-17-1066

Xing, D., Siva, S., and Hanna, G. G. (2019). The abscopal effect of stereotactic radiotherapy and immunotherapy: fool's gold or El dorado? Clin. Oncol. 31, 432-443. doi: 10.1016/j.clon.2019.04.006

Yin, X., Mason, J., Lobachevsky, P. N., Munforte, L., Selbie, L., Ball, D. L., et al. (2018). Radiotherapy modulates DNA repair efficiency in peripheral blood mononuclear cells of patients with non-small cell lung cancer. Int. J. Rad. Oncol. Biol. Phys. 103, 521-531. doi: 10.1016/j.ijrobp.2018. 10.001

Conflict of Interest: RM has a commercial interest associated with his intellectual property on DNA-binding radioprotectors.

The remaining author declares that the research was conducted in the absence of any commercial or financial relationships that could be construed as a potential conflict of interest.

Copyright (C) 2020 Martin and Martin. This is an open-access article distributed under the terms of the Creative Commons Attribution License (CC BY). The use, distribution or reproduction in other forums is permitted, provided the original author(s) and the copyright owner(s) are credited and that the original publication in this journal is cited, in accordance with accepted academic practice. No use, distribution or reproduction is permitted which does not comply with these terms. 